\title{
Cardiac Fibroblasts Recruit Th17 Cells Infiltration Into Myocardium by Secreting CCL20 in CVB3-Induced acute Viral Myocarditis
}

\author{
Miao Yu ${ }^{a, b}$ Jun Hu ${ }^{a, b}$ Ming-Xin Zhu ${ }^{a, b}$ Tong Zhao ${ }^{a}$ Wei Liang ${ }^{a}$ Shuang Wen ${ }^{a}$ \\ Huan-Huan Lia Qi Longa Min Wang ${ }^{a}$ He-Ping Guo ${ }^{a}$ Xiang Cheng ${ }^{a}$ Yu-Hua Liao \\ Jing Yuan ${ }^{\mathrm{a}}$ \\ aLaboratory of Cardiovascular Immunology, Institute of Cardiology, Union Hospital, Tongji Medical \\ College, Huazhong University of Science and Technology, Wuhan, China, bJoint first authors: \\ All of the three authors contributed to the work equally
}

\section{Key Words}

Th17 cells • Cardiac fibroblasts $\bullet$ CCL20 • Acute viral myocarditis

\begin{abstract}
Aims: Th17 cells contributed to myocardial inflammatory injury in acute viral myocarditis (AVMC), and the migration of these cells were mainly mediated by CCL20-secreting inflammatory cells. However, whether and how the resident cells such as cardiomyocytes and cardiac fibroblasts could mediate Th17 cell migration into the heart remains unclear in AVMC. Methods: The effect of CCL20 on the dynamic alterations of intracardiac Th17 cells and disease severity were investigated through the neutralization of CCL20 in AVMC mice. The key cells releasing CCL20 in the heart and the effects of CCL20-secreting cells on Th17 cell arrest, migration and differentiation were detected in vitro. Results: Neutralization of CCL20 efficiently repressed the myocardial inflammation along with the reduction of Th17 cell infiltrations in the course of AVMC. In vitro, after stimulations of TNF- $\alpha$, IL- $1 \beta$ and IL17 , cardiac fibroblasts rather than cardiomyocytes could be dominantly induced for CCL20 production. CCL20-secreting cardiac fibroblasts boosted Th17 cell arrest on endothelium, and induce Th17 cell migration. However, CCL20 produced by cardiac fibroblasts had no effect on Th17 cell differentiation and IL-17 production. Conclusions: It firstly suggested that cardiac fibroblasts could recruit Th17 cells infiltration into myocardium by secreting CCL20 in AVMC.
\end{abstract}

Jing Yuan

and Yu-Hua Liao
Laboratory of Cardiovascular Immunology, Institute of Cardiology,

Union Hospital, Jie-Fang Avenue 1277\#, Wuhan, 430022, (China)

E-Mail yhelen13@163.com and E-Mail liaoyh27@126.com 


\section{Cellular Physiology and Biochemistry}

Cell Physiol Biochem 2013;32:1437-1450

\begin{tabular}{l|l}
\hline DOI: $10.1159 / 000356581$ & (c) 2013 S. Karger AG, Basel
\end{tabular}

Yu et al.: Cardiac Fibroblasts Could Recruit Th17 Cells

\section{Introduction}

Acute viral myocarditis (AVMC) is characterized by the inflammatory cell infiltration in the heart [1-3]. CD4+ Th17 cells are important for the development of AVMC by enhancing virus replication, inflammatory injury, and autoantibody production [4-7]. In addition, Th17 cells and their characteristic cytokine IL-17 could mediate the apoptosis of cardiomyocytes and the activation of cardiac fibroblasts by cell contacts $[8,9]$. However, the mechanisms of the interactions between Th17 cells and these resident cells in the heart remain unclear.

Before Th17 cells exerting their effects on myocardial damage, they have to migrate into the myocardium. It is well established that chemokines play an important role in CD4 ${ }^{+}$ $\mathrm{T}$ cell migrations, and the expressions of chemokine receptors are different on $\mathrm{CD} 4^{+} \mathrm{T}$ cell subsets, which provide specificity to cell trafficking [10]. CXCR3 and CCR5 are preferentially expressed on Th1 cells, whereas CCR3 and CCR8 are mainly expressed on Th2 cells. The recent studies have revealed that CCR6, the specific receptor for CCL20 mainly secreted by inflammatory cells, is dominantly expressed on Th17 cells and mediates Th17 cell migration [11]. In this study, we found that the resident cardiac fibroblasts were involved in the recruitment of Th17 cells infiltrating into myocardium by secreting CCL20 in CVB3-induced AVMC besides the inflammatory cells.

\section{Materials and Methods}

\section{Mice}

Male BALB/c mice aged 4 weeks were purchased from the Hubei research centre of experimental animal in China. The experiment relevant to the care and use of animals in this study was performed under the Guide for the Care and Use of Laboratory Animals published by the United States National Institutes of Health and approved by the animal care committee of the University of Huazhong University of Science and Technology. Animals were housed under specific pathogen-free (SPF) mouse room in the experimental animal centre (Tongji Medical College of Huazhong University of Science and Technology).

\section{Virus}

The CVB3 (3m strain, CCTCC GDV115) was prepared by passage through Hela cells. The virus titer was $1 \times 10^{7}$, which was determined by plaque forming unit (PFU) assay of HeLa cell. BALB/c mice were infected with $0.2 \mathrm{ml}$ of RPMI-1640 (Gibco) containing approximately $10^{5} \mathrm{PFU}$ of the virus by an intraperitoneal (i.p) injection for establishing AVMC models.

\section{Interventions and groups}

BALB/c mice were randomly divided into four groups: (1) AVMC group ( $n=24)$ : mice were administrated with CVB3 and saline (100 $\mu$ l per mouse) i.p. on day 0; (2) CCL20 mAb group ( $n=24)$ : mice were treated with CVB3 and rat anti-mouse CCL20 mAb (100 ug per mouse, R\&D) i.p. on day 0; (3) Isotype control group $(n=24)$ : mice were injected with CVB3 and isotype control immunoglobulin (Ig) G1Ab (100 ug per mouse, eBioscience) i.p. on day 0. (4) Normal group ( $n=24)$ : BALB/c mice were not administrated anything else. On days 3, 5, 7 and 10 of this experiment, six animals of each group were randomly selected to be killed separately. The mice were anesthetized with an intraperitoneal injection of $10 \%$ chloralic hydras (5 ul / g). The heart rates, breathing rates, and autonomic reflexes were monitored. When the palpebral reflex was lost, blood was collected via retro-orbital bleeding and the serum was then prepared for detection. The method of exsanguination was used for the euthanasia of the anesthetized mice, and their hearts were removed freshly and aseptically for further measurements.

\section{Elecsys}

The concentrations of serum cardiac troponin (cTn) T were measured using the quantitative rapid assay kit (Roche Diagnostics $\mathrm{GmbH}$ ) by Elecsys as previously described [12]. All of the samples were measured in triplicate. 


\section{Cellular Physiology and Biochemistry}

Cell Physiol Biochem 2013;32:1437-1450

\begin{tabular}{l|l}
\hline DOI: $10.1159 / 000356581$ & (C) 2013 S. Karger AG, Basel
\end{tabular}

www.karger.com/cpb

Yu et al.: Cardiac Fibroblasts Could Recruit Th17 Cells

\section{Histopathology}

The ventricular tissues of the hearts were fixed in 10\% phosphate-buffered formalin. After trimming and embedding routinely in paraffin, $5 \mu \mathrm{m}$ sections were cut longitudinally and stained with H\&E (hematoxylin and eosin). The severity of CVB3-induced myocarditis was assessed as the percentage of inflammatory areas compared with the overall size of the heart section by a microscope eyepiece grid with magnification $\times 200$ according to the following scoring system: grade 0 , no; grade $1,<25 \%$ of the heart section is involved; grade $2,25 \%$ to $50 \%$; grade 3, 50\% to 75\%; grade 4, more than $75 \%$ [13]. Two independent researchers assessed separately in a double-blind manner.

\section{Immunohistochemistry}

To evaluate the tissue expression of IL-17, the heart sections were heated by microwave in $0.01 \%$ citrate buffer $(\mathrm{PH}=9.0)$ and treated with $3 \% \mathrm{H}_{2} \mathrm{O}_{2}$ for 10 min to inhibit endogenous peroxidase activity. After washing with PBS three times and blocking with $3 \%$ bovine serum albumin (BSA) for 30 min, sections were incubated with rat anti-mouse IL-17 antibody (eBioscience) at $4{ }^{\circ} \mathrm{C}$ overnight, and washed with PBS three times. Then the heart sections were incubated with HRP-conjugated anti-rat antibody (DaKo) for $45 \mathrm{~min}$. Finally, the diaminobenzidine solution was added, and then sections were counterstained by hematoxylin.

\section{Intracardiac flow cytometry analysis}

Hearts were minced into $1 \mathrm{~mm}^{3}$ small pieces and then digested in $0.1 \%$ collagenase B solution (Roche) for 6 minutes, 4 times, at $37^{\circ} \mathrm{C}$. Single cell suspension was prepared by filtering through a cell strainer ( 40 $\mu \mathrm{m}, \mathrm{BD}$ Falcon). After lysis of erythrocytes, the lymphocytes were isolated with Ficoll (GE) using density gradient centrifugation. The cells were resuspended at a density of $1.5 \times 10^{6} / \mathrm{ml}$, stained with FITC-labeled anti-mouse CD4 antibody (eBioscience), and stimulated with PMA (50 ng/ml, eBioscience), ionomycin ( $1 \mu \mathrm{g} / \mathrm{ml}$, eBioscience), and monensin $\left(1 \mu \mathrm{g} / \mathrm{ml}\right.$, eBioscience) at $37{ }^{\circ} \mathrm{C} / 5 \% \mathrm{CO}_{2}$ in a 24 -well culture plate (Costar) in RPMI-1640 medium (Gibco) supplemented with $100 \mathrm{U} / \mathrm{ml}$ of penicillin, $100 \mathrm{mg} / \mathrm{ml}$ of streptomycin, 10\% fetal calf serum (FCS, Gibco). Five hours later, the cells were harvested. After washing, fixing and permeabilizing, they were stained intracellularly with PEcy7-labeled anti-mouse IL-17A antibody (eBioscience) at $4{ }^{\circ} \mathrm{C}$ for $30 \mathrm{~min}$. The isotype-matched antibody (eBioscience) controls were used to regulate compensation and make sure the antibody specificity. The cells were finally acquired and analyzed by FACScalibur flow cytometry (BD Biosciences).

\section{Cell isolation}

Neonatal cardiomyocytes and cardiac fibroblasts were isolated as previously described [14, 15]. Briefly, ventricles from 1-3 days BALB/c mice killed by cervical dislocation were minced and digested in $0.05 \%$ trypsin (GIBCO) for $30 \mathrm{~min}$ at $4{ }^{\circ} \mathrm{C}$ with rotation. The digestion was stopped by FCS. After washing with HBSS, the tissues were incubated in $4 \mathrm{ml}$ Liberase $\mathrm{TH}\left(0.1 \mathrm{U} / \mathrm{ml}\right.$ in HBSS, Roche) at $37^{\circ} \mathrm{C}$ for $5 \mathrm{~min}$, and the supernatant containing the released cells was collected in DMEM medium containing $20 \%$ FCS. This digestion procedure in Liberase TH was repeated until most of the cells had been released from ventricular tissue. The collected cells were seeded into 12-well culture plates (Iwaki) and incubated with $5 \% \mathrm{CO}_{2}$ at $37{ }^{\circ} \mathrm{C}$ for 1 hour. Then the unattached cardiomyocytes in the supernatant were enriched and seeded into fibronectin-coated tissue culture plates after cell concentration adjusting. Cardiomyocytes were applied to the experiments when they formed a confluent monolayer and beat in synchrony at 72 hours. The attached fibroblasts were purified with discoidin domain receptor 2 antibodies (Santa cruz biotechnology) by flow cytometry. Then a part of these cardiomyocytes and fibroblasts were cultured in DMEM supplemented with $10 \%$ FCS and treated with TNF- $\alpha$, IFN- $\gamma$, IL-1 $\beta$, IL-6, or IL-17 (Peprotech) respectively to induce the production of CCL20. The CCL20 mRNA was tested by real-time PCR and CCL20 protein was detected by ELISA.

Myocardial endothelial cells were isolated from the hearts of 7-day-old BALB/c mice using a modification of published protocols $[16,17]$. Briefly, the mice were killed by cervical dislocation, and the hearts were separated, rinsed, and digested in an aseptic environment for $40 \mathrm{~min}$ at $37^{\circ} \mathrm{C}$ in $0.1 \%$ collagenase B solution (Roche). The digested material was applied to a cell strainer (70 $\mu \mathrm{m}$ size, BD Falcon) to isolate released cells. Then, the dissociated cells were incubated with biotin anti-mouse CD31 (Biolegend), and then with anti-biotin microbeads (Miltenyi). CD31 ${ }^{+}$endothelial cells were finally isolated according to the manufacture's instructions (Miltenyi). After purification, endothelial cells were cultured in endothelial 


\section{Cellular Physiology and Biochemistry}

Cell Physiol Biochem 2013;32:1437-1450

\begin{tabular}{l|l}
\hline DOI: $10.1159 / 000356581$ & (C) 2013 S. Karger AG, Basel
\end{tabular}

www.karger.com/cpb

Yu et al.: Cardiac Fibroblasts Could Recruit Th17 Cells

cell medium containing endothelial cell growth supplement (1\%, ScienCell). When the cells reached $80 \%$ confluence, they were sorted for the second time with biotin anti-mouse ICAM-2 (Biolegend) and anti-biotin microbeads (Miltenyi). Purity of the cells was over $85 \%$, which was determined by staining for PE antimouse CD31 (eBioscience) and flow cytometry analysis. Endothelial cells from passages 1 to 3 were used in this study.

The splenic $\mathrm{CD}^{+}{ }^{+} \mathrm{T}$ cells for adhesion, migration and differentiation experiments were purified by negative selection using mouse $\mathrm{CD}^{+} \mathrm{T}$ cell isolation kit (Miltenyi Biotech) from AVMC mice that were sacrificed by cervical dislocation, and these $\mathrm{CD} 4^{+} \mathrm{T}$ cell were further positively selected by mouse IL-17 secretion assay - cell enrichment and detection kit (PE) to get the purified Th17 cells according to the manufacture's instructions.

\section{Cell arrest assay}

Myocardial endothelial cells containing $1 \times 10^{5}$ cells in 400 ul endothelial cell medium were seeded on the basolateral side of the upper chamber in the 24 -hole transwell $(0.4 \mu \mathrm{m}$ pore, Corning). After endothelial cells forming a monolayer, neonatal cardiac fibroblasts were added in the lower chamber at a density of $1 \times 10^{5}$ cells per $600 \mathrm{ul}$ in DMEM medium containing $10 \mathrm{mM}$ HEPES, $10 \%$ FCS. Two days later, Th17 cells were stained with FITC-labeled anti-mouse CD 4 antibody (eBioscience) and then loaded onto the upper chamber at a density of $1 \times 10^{6}$ cells per $100 \mathrm{ul}$ for each individual assay. After 1 hour of incubation at $37^{\circ} \mathrm{C}$ on a rocking device, non-adherent cells were removed by three gentle washes with PBS. Adherent cells were counted in six randomly chosen fields using fluorescence microscopy by two independent researchers in a double-blind manner [18]. The endothelial cells on the basolateral side of the upper chamber were gathered for the expressions of ICAM-1 and VCAM-1 by real-time PCR.

\section{Cell migration assay}

Neonatal cardiac fibroblasts were seeded in the lower chamber of the 24-hole transwell (5 $\mu \mathrm{m}$ pore, Corning) at a density of $1 \times 10^{5}$ cells per $600 \mathrm{ul}$ in DMEM medium containing $10 \mathrm{mM}$ HEPES, $1 \%$ FCS. Th17 cells were stained with FITC-labeled anti-mouse CD4 antibody (eBioscience) and then loaded onto the upper chamber at a density of $5 \times 10^{5}$ cells per $100 \mathrm{ul}$ for each individual assay. After $8 \mathrm{~h}$ at $37^{\circ} \mathrm{C} / 5 \% \mathrm{CO}_{2^{\prime}}$ the number of cells migrating into the lower chamber was determined in six randomly chosen fields using a fluorescence microscope by two independent researchers in a double-blind manner. The expressions of CCR6 were tested by Allophycocyanin (APC)-labeled anti-mouse CCR6 antibody (R\&D) by flow cytometry as mentioned above. Mouse CCR6 mAb (R\&D) was used for CCR6 antagonism, and IgG2aAb was the isotype control.

\section{Cell differentiation assay}

The purified $\mathrm{CD}^{+} \mathrm{T}$ cells $\left(2 \times 10^{6}\right.$ cells $\left./ \mathrm{ml}\right)$ were co-cultured with or without isolated neonatal cardiac fibroblasts $\left(1 \times 10^{5}\right.$ cells / $\left.\mathrm{ml}\right)$ for $3 \mathrm{~d}$ at $37^{\circ} \mathrm{C} / 5 \% \mathrm{CO}_{2}$ in a 24-well culture plate (Corning) in DMEM medium containing $100 \mathrm{U} / \mathrm{ml}$ of penicillin, $100 \mathrm{ug} / \mathrm{ml}$ of streptomycin, $10 \% \mathrm{FCS}, 3 \mathrm{ug} / \mathrm{ml}$ anti-mouse CD3 (eBioscience, California, USA), and $10 \mathrm{ug} / \mathrm{ml}$ anti-mouse CCL20 mAb or isotype control IgG1Ab separately. The percentages of Th17 cells were detected with FITC-labeled anti-mouse CD4 antibody (eBioscience) and PEcy7-labeled anti-mouse IL-17 antibody (eBioscience) by flow cytometry as mentioned above. The IL-17 levels in the supernatant were tested by ELISA.

\section{Real-time PCR}

The total RNA of neonatal cardiomyocytes/cardiac fibroblasts with different cytokine stimulations and myocardial endothelial cells in the arrest assay were isolated using Trizol (Invitrogen, Carlsbad, California), and the single-stranded cDNA was produced by reverse transcription with the Reverse Transcriptase kit (Takara, Japan). The sequences of the primers are shown as follows: GAPDH (F: CACGGCAAATTCAACGGC, R: TGATGACCCTTTTGGCTCCA), CCL20 (F: CCTCTCGTACATACAGACGCCTC, R: TTGACTCTTAGGCTGAGGAGGTTC), ICAM-1 (F: TGGTTCTTCTGAGCGGCGT, R: TGGTTCTTCTGAGCGGCGT), and VCAM-1 (F: TGTGGAAATGTGCCCGAAAC, R: GATCATCCCGATGGCAGGTAT). The mRNA expressions of CCL20 in neonatal cardiomyocytes/cardiac fibroblasts and ICAM-1/VCAM-1 on myocardial endothelial cells were measured with SYBR @ Premix Ex Taq ${ }^{\mathrm{TM}}$ II (Takara, Japan) and the Applied 7000 (Applied Biosystem) by Real-Time-PCR. After the initial denaturation step at $94^{\circ} \mathrm{C}$ for $3 \mathrm{~min}$, a three-step cycle procedure was 


\section{Cellular Physiology and Biochemistry}

Cell Physiol Biochem 2013;32:1437-1450

\begin{tabular}{l|l}
\hline DOI: $10.1159 / 000356581$ & (c) 2013 S. Karger AG, Basel
\end{tabular}

Publisned onine: November 28, $2013 \quad$ www.karger.com/cpb

Yu et al.: Cardiac Fibroblasts Could Recruit Th17 Cells

performed (denaturation $94{ }^{\circ} \mathrm{C}, 30 \mathrm{~s}$; annealing $58^{\circ} \mathrm{C}, 30 \mathrm{~s}$; and extension $72{ }^{\circ} \mathrm{C}, 30 \mathrm{~s}$ ) for 40 cycles, and the relative mRNA expressions were normalized to the level of GAPDH.

\section{ELISA}

The CCL20 productions in the heart of BALB/c mice with different treatments were tested by the CCL20 ELISA kits (RayBiotech). Briefly, the ventricular tissues of the hearts were collected in 100ul protein extraction buffer (Pierce) to homogenates. The protein concentration was determined by the BCA protein assay kit (Pierce). Samples containing $500 \mu \mathrm{g}$ proteins in 100ul PBS were applied to the ELISA system according to the manufacturer's instructions.

The CCL20 secretions in supernatant of neonatal cardiomyocytes/cardiac fibroblasts with different cytokine stimulations were detected by the CCL20 ELISA kits (RayBiotech) according to the manufacturer's instructions.

The IL-17 secretion in the co-cultured CD4+ $\mathrm{T}$ cells and cardiac fibroblasts were determined by the IL17 ELISA kits (eBioscience) according to the manufacturer's instructions.

The sensitivities of these two ELISA kits are $3 \mathrm{pg} / \mathrm{ml}$ for CCL20 and $1.6 \mathrm{pg} / \mathrm{ml}$ for IL-17 separately, and there was no cross-reactivity detected.

Statistical analysis

Data were shown as the mean \pm SEM. Statistical analysis of the data was performed with one-way ANOVA using SPSS11.0. $\mathrm{P}<0.05$ was considered statistically significant.

\section{Results}

The severity of AVMC mice

The ratios of HW/BW (heart weight to body weight), serum cTnT levels and the pathological scores of heart sections in AVMC, CCL20mAb and isotype control groups were elevated significantly compared with those in normal group on days 3, 5, 7 and 10 (all $\mathrm{p}<0.05$ ). These progressive alterations began on day 3 and peaked on day 7 . However, these three indexes evaluating for the disease severity in CCL20mAb group were less than those in AVMC and isotype control groups (all p<0.05) on days 5, 7 and 10 , especially on day 7 , and there was no significant difference between AVMC and isotype control groups. The differences of these three indexes were not obvious between AVMC, CCL20mAb and isotype control groups on day 3 (Fig. 1 A-D).

CCL20 levels in the hearts in AVMC, CCL20mAb and isotype control groups were increased significantly compared with those in normal group on days 3, 5, 7 and 10 (all $\mathrm{p}<0.05$ ). And the expressions of CCL20 in CCL20mAb group were reduced compared with those in AVMC and isotype control groups on days 3, 5, 7 and 10 (all p<0.05, Fig. $1 \mathrm{E}$ ).

In addition, on days 3, 5, 7 and 10, there were no changes observed in normal controls (Fig. 1 A-E).

The percentages of intracardiac Th17 cells in AVMC mice

Th17 cells that infiltrated into the myocardium in the course of AVMC were analyzed. Firstly, we detected the numbers of IL-17-releasing cells in the heart, and found that the infiltrations appeared on day 5, culminated on day 7. Moreover, on days 5, 7 and 10, the numbers of IL-17-secreting cells increased significantly in AVMC, CCL20mAb and isotype control groups compared with those in normal group (all $\mathrm{p}<0.05$ ), but they were reduced in CCL20mAb group than those in AVMC and isotype control groups (all $\mathrm{p}<0.01$ ). There was no significant difference between AVMC and isotype control groups. And few IL-17-producing cells were observed in normal controls on days 3, 5, 7 and 10 (Fig. $2 \mathrm{~A}$ and B).

The phenotypic assay of the infiltrating IL-17-secreting cells was carried out by flow cytometry. It revealed that the percentages of intracardiac CD4+ Th17 cells were obviously higher in AVMC, CCL20mAb and isotype control groups than those in normal group on day 7 and 10 (all $\mathrm{p}<0.01$ ). And the elevations of intracardiac Th17 cells were attenuated 


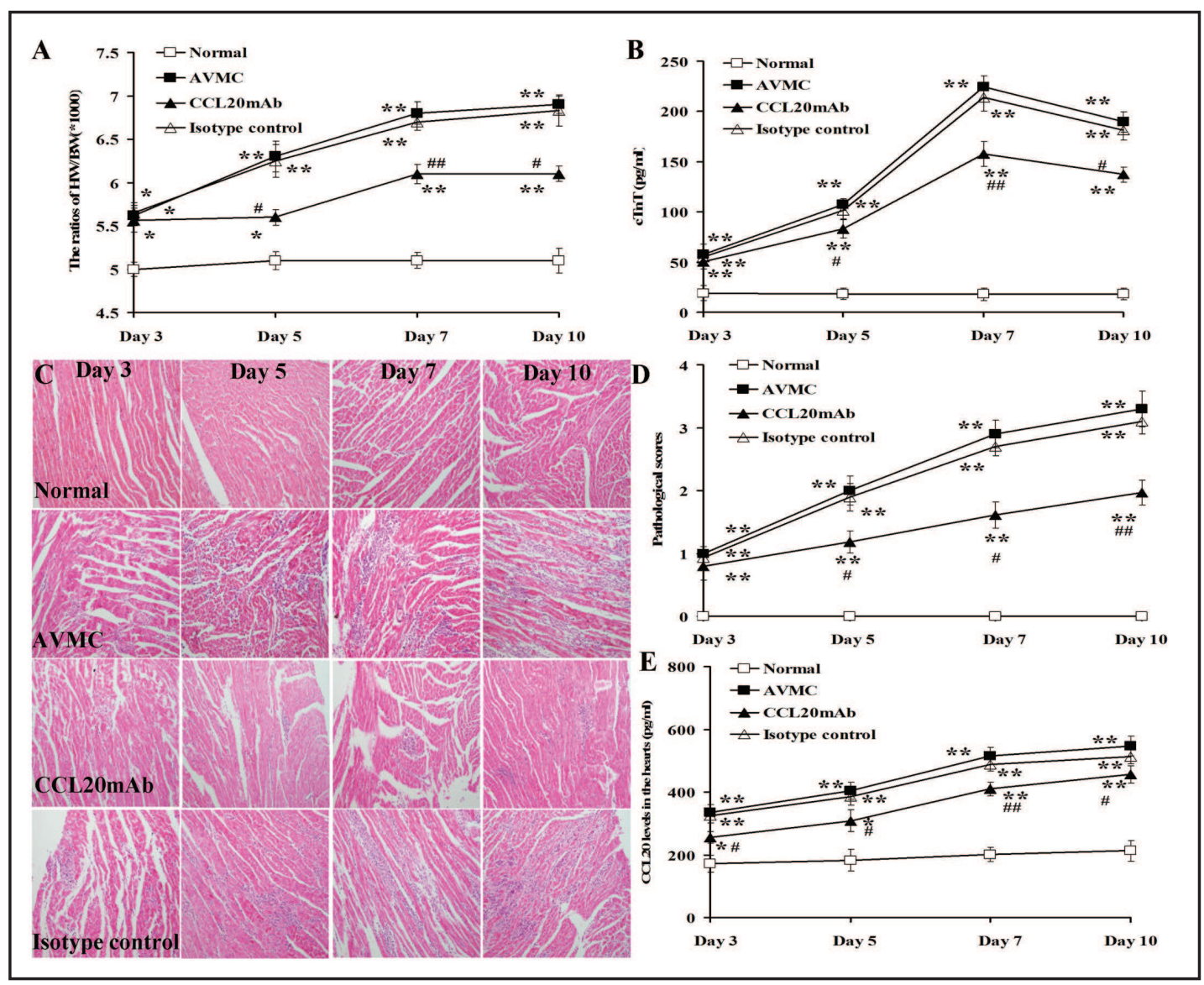

Fig. 1. The severity of AVMC mice. (A) The ratios of HM/BW. (B) The levels of serum cTnI. (C) The representative pictures of histopathology (magnification $\times 200$ ) in heart tissue. (D) The pathological scores in different groups. (E) The CCL20 protein levels in the hearts in different groups. Six mice per group were analyzed for each time point. ${ }^{*}, \mathrm{p}<0.05$ vs Normal group; ${ }^{* *}, \mathrm{p}<0.01$ vs Normal group. \#, $\mathrm{p}<0.05$ vs AVMC and isotype control groups; \#\#, $\mathrm{p}<0.01$ vs AVMC and isotype control groups. Values are means \pm SEM.

in CCL20mAb group compared with those in AVMC and isotype control groups on days 7 and $10(\mathrm{p}<0.01)$. No significant difference was existed between AVMC and isotype control groups. There were few intracardiac Th17 cells in all of the groups on days 3 and 5, and also in normal groups on days 7 and 10 (Fig. $2 \mathrm{C}$ and D).

The percentages of splenic Th17 cells were obviously higher in AVMC, CCL20mAb and isotype control groups than those in normal group on days 5, 7 and 10 (all p<0.05). And splenic Th17 cell percentages in AVMC and isotype control groups were also higher than those in normal group on day $3(\mathrm{p}<0.05)$. But the splenic Th17 cells were decreased in CCL20mAb group compared with those in AVMC and isotype control groups on day 5, 7 and 10 (all $\mathrm{p}<0.05$ ). No markedly difference of splenic Th17 cells percentages were observed in normal controls on days 3, 5, 7 and 10 (Fig. $2 \mathrm{E}$ and F).

The expression of CCL20 in cardiomyocytes and cardiac fibroblasts

In order to explore the main CCL20-secreting cells in the heart, the neonatal cardiomyocytes and cardiac fibroblasts were isolated. TNF- $\alpha$, IFN- $\gamma$, IL-1 $\beta$, IL-6, and IL-17 were the key proinflammatory cytokines in viral myocarditis. So these isolated cells were stimulated with these cytokines respectively. It indicated that both of the CCL20 mRNA and protein were highly expressed in cardiac fibroblasts. Moreover, the expressions of CCL20 were remarkably increased with the treatment of TNF- $\alpha$, IL-1 $\beta$ or IL-17 (all p<0.05), and 


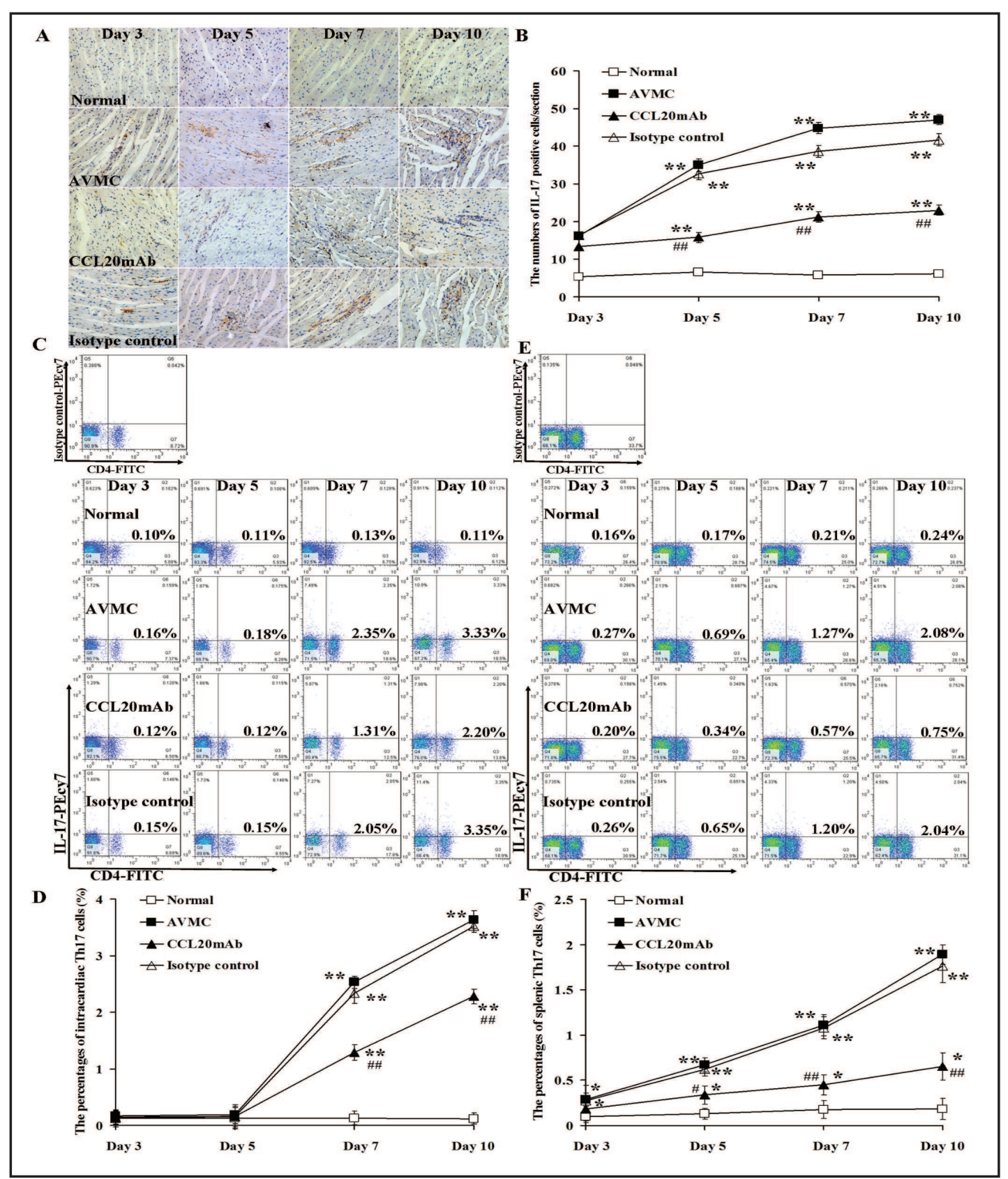

Fig. 2. The percentages of intracardiac Th17 cells in AVMC mice. (A) The representative immunohistochemical pictures of IL-17-releasing cells in the hearts (magnification $\times 400$ ). (B) The results of the statistical analysis for the numbers of IL-17-releasing cells in the heart sections. (C) Representative pictures for intracardiac CD $4^{+}$IL-17+ Th17 cells in each group by flow Cytometry. Numbers in the upper right quadrants indicate the percents of Th17 cells. (D) The results of statistical analysis for the alteration of intracardiac Th17 cells. (E) Representative pictures for splenic CD4+ IL-17+ Th17 cells in each group by flow Cytometry. Numbers in the upper right quadrants indicate the percents of Th17 cells. (F) The results of statistical analysis for the alteration of splenic Th17 cells.*, p<0.05 vs Normal group; **, p<0.01 vs Normal group; \#, p<0.05 vs AVMC and isotype control groups; \#\#, $\mathrm{p}<0.01$ vs AVMC and isotype control groups. Six mice per group were analyzed for each time point. Values are means \pm SEM.

unchangeable with the administration of IFN- $\gamma$ or IL- 6 compared with the cardiac fibroblasts without stimulations (Fig. 3A and B). For cultured cardiomyocytes, although they could 


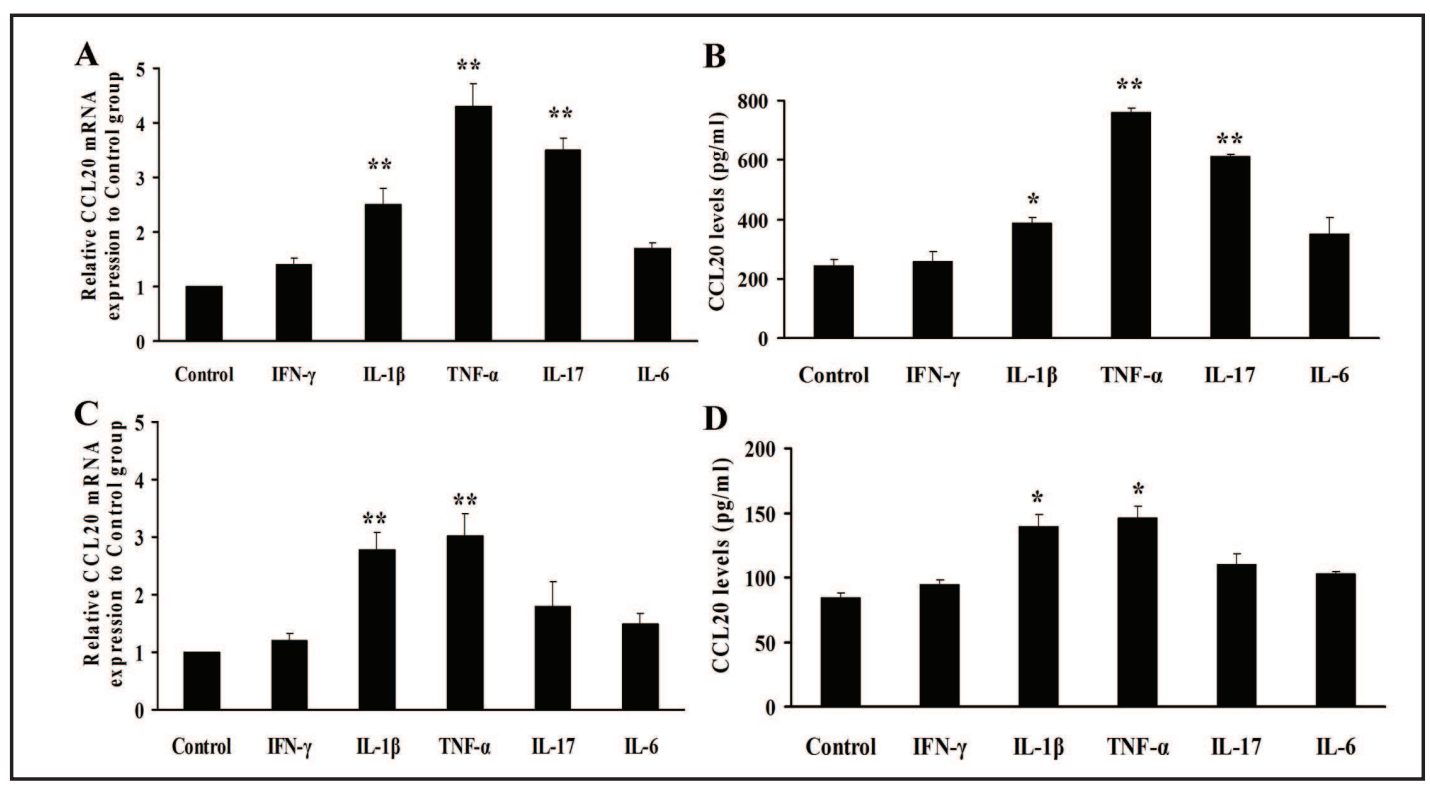

Fig. 3. The expression of CCL20 in cardiomyocytes and cardiac fibroblasts. (A) The mRNA levels of CCL20 in cardiac fibroblasts. (B) The results of ELISA for the protein levels of CCL20 in cardiac fibroblasts. (C) The mRNA levels of CCL20 in cardiomyocytes. (D) The results of ELISA for the protein levels of CCL20 in cardiomyocytes. *, p<0.05 vs Control group; ${ }^{* *}, \mathrm{p}<0.01$ vs Control group. Values are means \pm SEM.

also secrete CCL20, the expressions were much lower than those in cardiac fibroblasts. Furthermore, the expressions of CCL20 protein in cardiomyocytes were slightly enhanced with the stimulations of TNF- $\alpha(\mathrm{p}<0.05)$ and IL- $1 \beta(\mathrm{p}<0.05)$ rather than IL-17, IFN- $\gamma$ or IL-6 (Fig. 3C and D).

The influence of CCL20-secreting cardiac fibroblasts on Th17 cell arrest

The arrest of peripheral blood lymphocytes on endothelial cells lining the blood vessels is essential for lymphocyte trafficking into inflammatory tissue. We chose the most effective stimulator TNF- $\alpha$ for inducing CCL20 production from cardiac fibroblasts. Thus, the cardiac fibroblasts in the lower chamber of the transwell were stimulated with saline, TNF- $\alpha$, TNF$\alpha+$ CCL20mAb or TNF- $\alpha+$ isotype control to investigate whether CCL20-secreting cardiac fibroblasts mediating Th17 cell arrest on myocardial endothelial cells. We found that the numbers of Th17 cell adhering to myocardial endothelial cells in the upper chamber of the transwell were increased in TNF- $\alpha$, TNF- $\alpha+$ CCL20mAb and TNF- $\alpha+$ isotype control groups compared with the saline group. Furthermore, the arrest of Th17 cell was alleviated in TNF$\alpha+$ CCL20mAb group compared with TNF- $\alpha$ group and TNF- $\alpha+$ isotype control group, but the isotype control Abs did not have such effect (Fig. 4A and B).

Then we detected the adhesion molecule expressions on the myocardial endothelial cells to clarify the different Th17 cell arrest. It showed that the mRNA levels of ICAM-1 and VCAM-1 were elevated on myocardial endothelial cells in the upper chamber after cardiac fibroblasts were treated with TNF- $\alpha$ in the lower chamber. If CCL20 was neutralized by CCL20mAb in the culture system, these two adhesion molecule mRNA expressions were attenuated, and the administration of isotype control Abs did not influence their expressions (Fig. 4C).

The effect of CCL20-secreting cardiac fibroblasts on Th17 cell migration

To test the roles of cardiac fibroblasts in Th17 cell migration, we also treated the cardiac fibroblasts in the lower chamber of the transwell with saline, TNF- $\alpha$, TNF- $\alpha+$ CCL20mAb or TNF- $\alpha+$ isotype control. The numbers of Th17 cell migrating to CCL20-secreting cardiac fibroblasts in the lower chamber were higher in TNF- $\alpha$, TNF- $\alpha+$ CCL20mAb and TNF- 


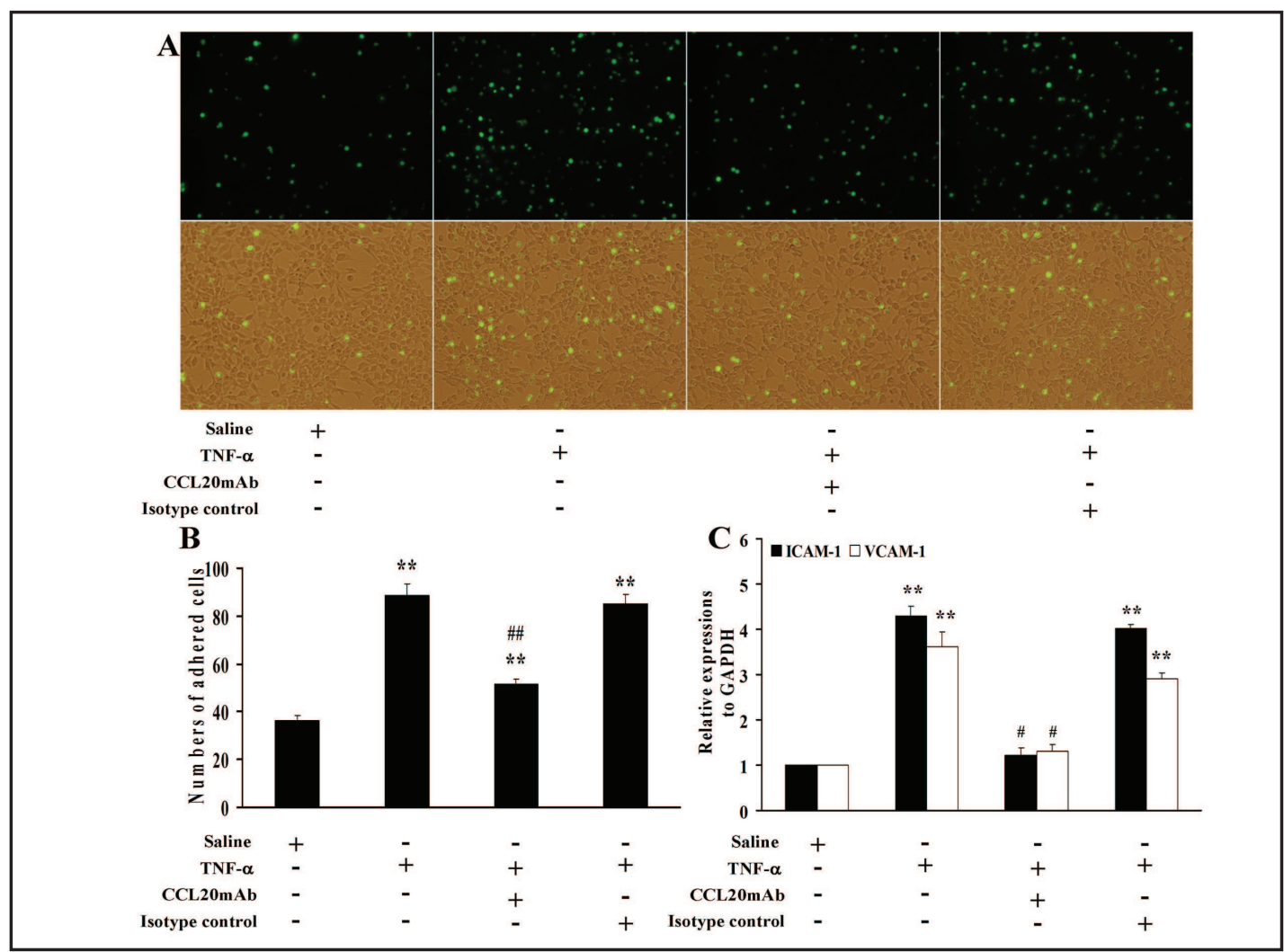

Fig. 4. The influence of CCL20-secreting cardiac fibroblasts on Th17 cell arrest. (A) The representative pictures for Th17 cell adhering to myocardial endothelial cells. The upper pictures showed the arrested Th17 cells (green) with immunofluorescence staining, and the lower pictures showed the merge of arrested Th17 cells detected by fluorescence microscope and the myocardial endothelial cells detected by inverted microscope. (B) The statistical analysis of the numbers of arrested Th17 cells on myocardial endothelial cells. (C) The mRNA levels of ICAM-1 and VCAM-1 on myocardial endothelial cells. ${ }^{* *}, \mathrm{p}<0.01$ vs Saline group; \#, $\mathrm{p}<0.05$ vs TNF- $\alpha$ and TNF- $\alpha+$ isotype control groups; \#\#, $\mathrm{p}<0.01$ vs TNF- $\alpha$ and TNF- $\alpha+$ isotype control groups. Values are means \pm SEM.

$\alpha+i$ sotype control groups than saline group. The increased Th17 cells in the lower chamber were reduced in TNF- $\alpha+$ CCL20mAb group compared with TNF- $\alpha$ group and TNF- $\alpha+$ isotype control group. The difference between TNF- $\alpha$ group and TNF- $\alpha+$ isotype control group was not significant (Fig. 5A).

Then we investigated the CCR6 expressions on the migrated Th17 in the lower chamber of the transwell. It showed no remarkable changes among TNF- $\alpha$, TNF- $\alpha+C C L 20 \mathrm{mAb}$ and TNF- $\alpha+$ isotype control groups (Fig. 5B).

To further explore whether Th17 cell chemotaxis was depended on CCR6, we preincubated the Th17 cells in the upper chamber of the transwell with saline, CCR6mAb or isotype control, and administrated the cardiac fibroblasts in the lower chamber with TNF- $\alpha$. The results showed that Th17 cell migrations in the CCR6mAb group were far less than those in saline and isotype control groups (Fig. 5C and D).

The role of CCL20-secreting cardiac fibroblasts in Th17 cell differentiation

To assess whether CCL20 secreted by cardiac fibroblasts acted on Th17 differentiation, we co-cultured purified $\mathrm{CD} 4^{+} \mathrm{T}$ cells with or without cardiac fibroblasts by the administrations of saline, CD3mAb, CD3mAb+CCL20mAb or CD3mAb+isotype control. Firstly, we found that the percentages of Th17 cells (CD4+ $\mathrm{IL}^{-17^{+}}$) and the secretions of IL-17 in the CD4+ $4^{+}$cells cocultured with cardiac fibroblasts were higher than those without cardiac fibroblasts under 
A

a

b

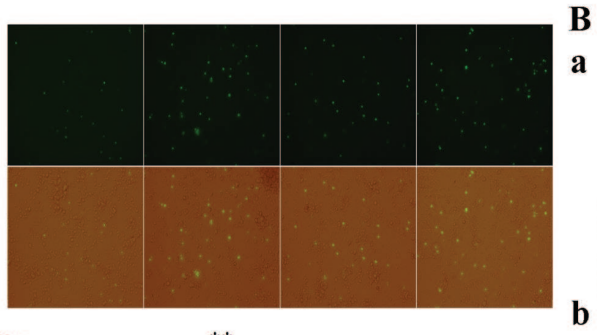

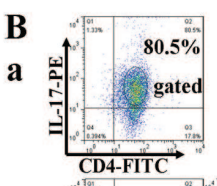

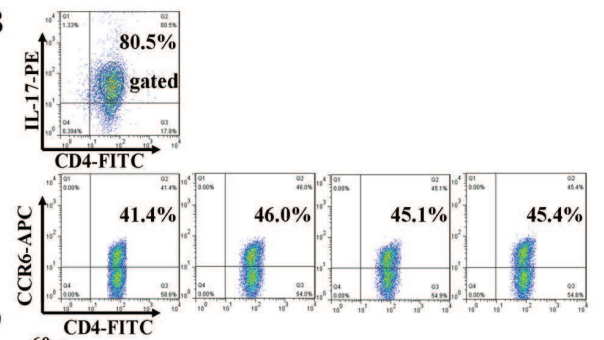

CD4-FITC
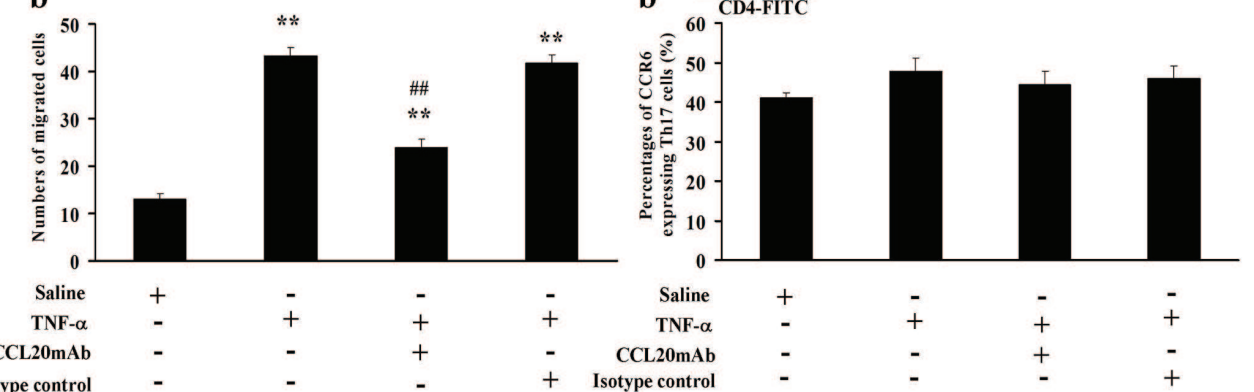

Isotype contro

C
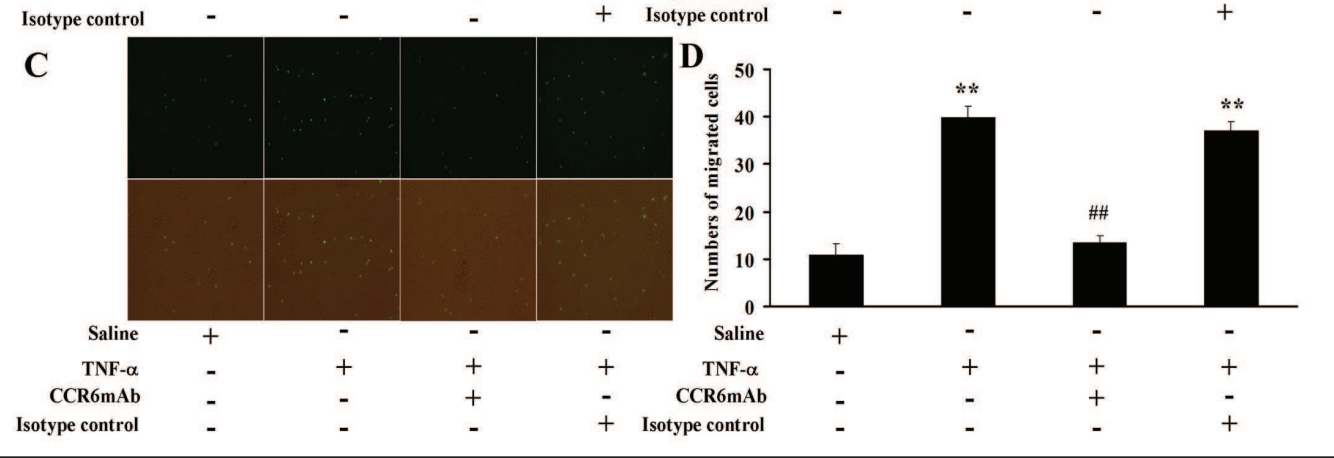

Fig. 5. The effect of CCL20-secreting cardiac fibroblasts on Th17 cell migration. (A) a, The representative pictures for Th17 cell migrating to CCL20-secreting cardiac fibroblasts. The upper pictures showed the migrated Th17 cells (green) with immunofluorescence staining, and the lower pictures showed the merge of migrated Th17 cells detected by fluorescence microscope and the cardiac fibroblasts detected by inverted microscope. b, The statistical analysis of the numbers of migrated Th17 cells to CCL20-secreting cardiac fibroblasts. (B) a, The upper picture showed that the purity of isolated Th17 cells was over $80 \%$. The lower representative pictures showed the CCR6 expressions on the migrated Th17 by flow cytometry. b, The statistical analysis for the CCR6 expressions on the migrated Th17. (C) The representative pictures for Th17 cell migrating to CCL20-secreting cardiac fibroblasts with CCR6 antagonists. (D) The statistical analysis of the numbers of migrated Th17 cells to CCL20-secreting cardiac fibroblasts with CCR6 antagonists. **, p<0.01 vs Saline group; \#\#, p<0.01 vs TNF- $\alpha$ and TNF- $\alpha+$ isotype control groups. Values are means \pm SEM.

the treatment of CD3mAb (all p<0.05). Then, it showed that the frequencies of Th17 cells and the secretions of IL-17 were increased in the co-culture system treating with CD3mAb, $\mathrm{CD} 3 \mathrm{mAb}+\mathrm{CCL} 20 \mathrm{mAb}$, and CD3mAb+isotype control compared with those with saline alone (all $\mathrm{p}<0.05$ ), but they were not significantly different among the co-culture system treating with CD3mAb, CD3mAb+CCL20mAb, and CD3mAb+isotype control (Fig. 6A-C).

\section{Discussion}

Cardiac fibroblasts contributed to the developments of myocarditis by mediating myocardial fibrosis, although the inflammatory cells especially the $\mathrm{CD} 4^{+}$Th17 were the main participators in the pathogenesis of this disease [9]. Recently, Antoniak et al have revealed that cardiac fibroblasts could recruit NK cells by secreting CXCL10 and inhibit viral 


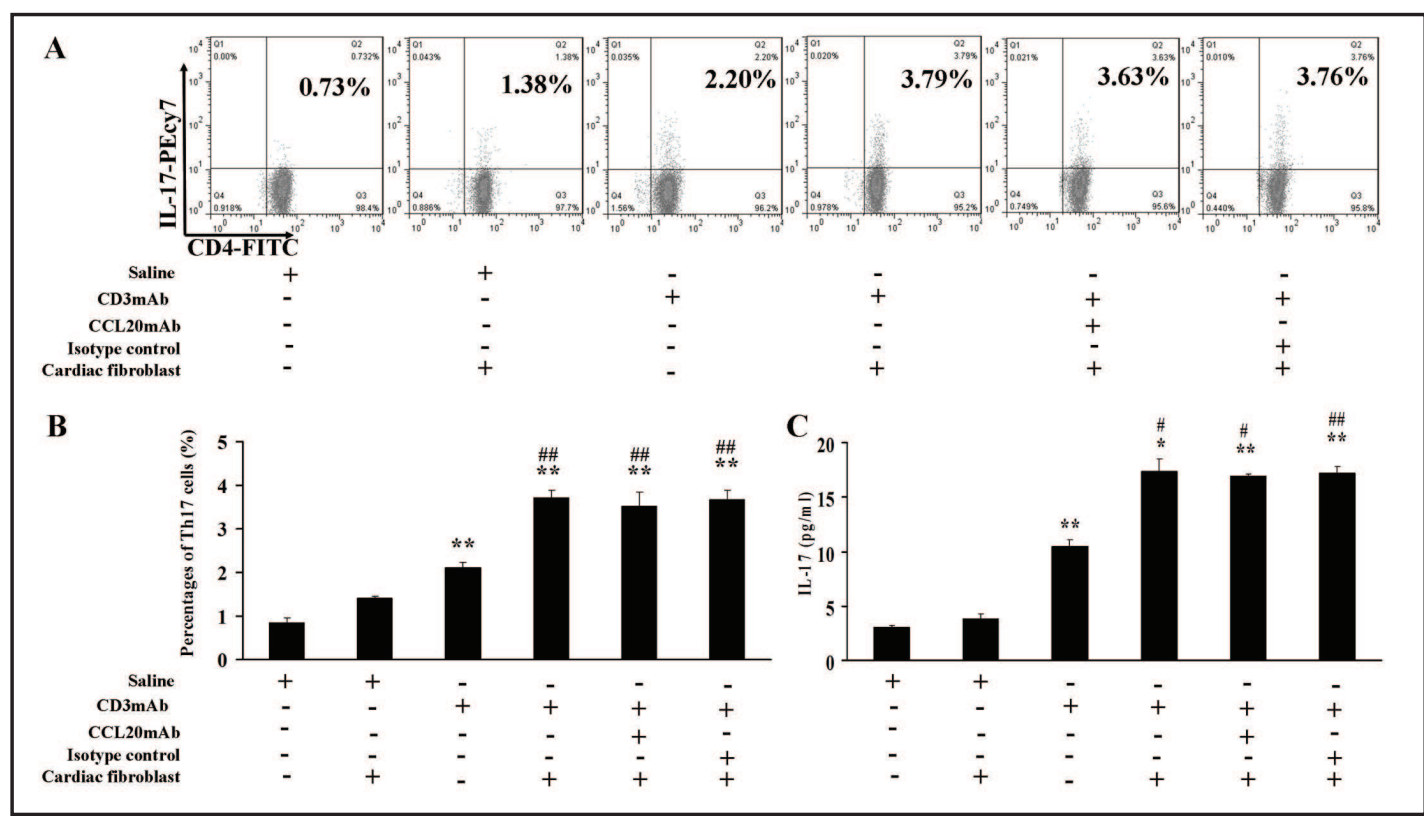

Fig. 6. The role of CCL20-secreting cardiac fibroblasts in Th17 cell differentiation. (A) Representative pictures for CD4+ IL-17+ Th17 cells in each group. Numbers in upper right quadrants indicate the percents of Th17 cells. (B) The results of statistical analysis for Th17 cells levels. (C) The protein levels of IL-17 in supernatant of the cells in the different groups tested by ELISA. *, $\mathrm{p}<0.05$ vs Saline and Saline+Cardiac fibroblasts group; **, p<0.01 vs Saline and Saline+Cardiac fibroblasts group; \#, $\mathrm{p}<0.05$ vs CD3mAb group; \#\#, $\mathrm{p}<0.01$ vs $\mathrm{CD} 3 \mathrm{mAb}$ group. Values are means $\pm \mathrm{SEM}$.

replication [19]. However, the role of cardiac fibroblasts in Th17 cells chemotaxis remains unknown in AVMC.

CCL20/CCR6 has been considered to be the key regulators of Th17 cell trafficking under inflammatory conditions in a few diseases such as glomerulonephritis, experimental autoimmune encephalomyelitis, and rheumatoid arthritis [20-22]. In this study, firstly, we further proved that the neutralization of CCL20 was found efficiently to repress the development of myocardial inflammation along with the reduction of Th17 cell infiltrations in AVMC. It then indicated that CCL20 might also be the important chemokine mediating Th17 cell infiltrating into myocardium in myocarditis.

Thus, we wanted to know whether cardiac fibroblasts could secrete CCL20 besides the other cells including macrophages, epithelial cells, Th17 cells, etc [23, 24]. After investigation, our study showed that cardiac fibroblasts rather than cardiomyocytes were the main cardiogenic CCL20-releasing cells stimulated in vitro. Previously, Hirata et al reported that TNF- $\alpha$, IL-1 $\beta$ and IL-17 coud activate the CCL20 promoter AP- 1 and mediate the CCL20 expression at the transcriptional level [24-26]. In this study, the CCL20 expressions in cardiac fibroblasts were also be regulated by those specific cytokines, which might be indicated that there was no molecular difference in CCL20 from cardiac fibroblasts and other proinflammatory cells. The mechanism of cardiac fibroblasts secreting CCL20 in inflammatory conditions might due to the activations of the MAPKs signaling pathway.

The steps of lymphocyte migration into target tissues from blood vessels mainly include the arrest on vascular endothelial cell, and finally transmigration through the endothelium [27-29]. To investigate the function of CCL20-secreting cardiac fibroblasts in Th17 cell infiltration into myocardium, we used the transwell to mimic this microenvironment and found that cardiac fibroblasts given the stimulation with TNF- $\alpha$ boosted Th17 cell arrest on endothelium. Meanwhile, neutralization of CCL20 in the microenvironment reduced the arrest of Th17 cells, which implied that cardiac fibroblasts could facilitate Th17 cell arrest on myocardial endothelial cells through CCL20 secretion. Adhesion molecules ICAM-1 and 


\section{Cellular Physiology and Biochemistry}

Cell Physiol Biochem 2013;32:1437-1450

\begin{tabular}{l|l}
\hline DOI: $10.1159 / 000356581$ & (C) 2013 S. Karger AG, Basel
\end{tabular}

www.karger.com/cpb

Yu et al.: Cardiac Fibroblasts Could Recruit Th17 Cells

VCAM-1 are the important molecules for the arrest of leukocytes in the blood vessels [30]. In this study, we further found that CCL20mAb suppressed the expressions of ICAM-1 and VCAM-1, which provided the evidence that CCL20 might contribute to Th17 cells arrest by enhancing adhesion molecule expressions on endothelium. In addition, Chen et al reported that CVB3 induced the biological changes of myocardial endothelial cells, which probably induced these endothelial cells transition to cardiac fibroblasts [31]. The impairment of endothelial cells and the increase of cardiac fibroblasts might further facilitate the entry of Th17 cells into myocardium, which provided more evidences for the interactions of myocardial endothelial cells and cardiac fibroblasts.

Subsequently, the effects of CCL20-secreting cardiac fibroblasts on Th17 cell migration were tested by transwell. The result showed that TNF- $\alpha$-stimulating cardiac fibroblasts induced Th17 cell migration, and the neutralization of CCL20 in this system inhibited the migration of Th17 cells, which implied that cardiac fibroblasts could mediate Th17 cell migration by producing CCL20. Although CCR6 is the specific ligand for CCL20 and plays the important role in Th17 cell migrations, the results of our study showed that CCL20 secreted by cardiac fibroblasts did not work on CCR6 expression modulations. Hence, we blocked the combination of CCR6 and CCL20, and found that inhibition of CCR6 function effectively reduced Th17 cell chemotaxis. It suggested that the effect of CCL20 secreted by cardiac fibroblasts on Th17 cell migration might rely on the activation of CCR6 signaling pathway instead of directly boosting the receptor expression.

After migration into target tissues, lymphocytes would become reactivated and further differentiated to amplify the local inflammation. Therefore, we assessed the influence of CCL20 on Th17 cell functions by cell co-culture. Although cardiac fibroblasts could promote Th17 cell functions, CCL20 secreted by cardiac fibroblasts had no effect on Th17 cell differentiation and IL-17 production. It indicated that the infiltrations of Th17 cells in myocardium mediated by CCL2 0 secreted from cardiac fibroblasts were mainly depended on the chemotaxis in AVMC. And these results further explained that the reduction of Th17 cells in spleen by CCL20 neutralization might also attribute to the inhibition of chemotaxis not the local generation.

In conclusion, we firstly proved that cardiac fibroblasts could mediate Th17 cells migration and finally infiltration into myocardium by secreting CCL20 in the course of AVMC. According to the fact that the neutralization of CCL20 improved the severity of disease and Th17 cell infiltrations, CCL20-secreting cardiac fibroblasts might be a target for regulating the Th17 cell migration in the hearts. In addition, although Th17 cells were the main cells expressing IL-17, other cells such as $\gamma \delta$ T cells and neutrophil granulocyte could also be the important source of IL-17 [32, 33]. In this study, we found that CD4- IL-17+ cells emerged in AVMC, and our another unpublished study proved that these $\mathrm{CD} 4 \mathrm{IL}^{-}-17^{+}$cells in the heart during AVMC were mainly neutrophil granulocyte and macrophage. Neutralization of CCL20 could also reduce the infiltration of these $\mathrm{CD}^{-} \mathrm{IL}^{-1} 7^{+}$cells, and the mechanisms need our further investigations. Besides, our study has some other limitations. The cardiac fibroblasts in adult AVMC mice were difficult to be isolated and cultured, so we only tested the secretion of CCL20 in neonatal cardiac fibroblasts. And the mechanisms of Th17 cell differentiation mediated by cardiac fibroblasts need our further exploration.

\section{Conflict of Interest}

None declared.

\section{Acknowledgements}

This work was supported by the National Natural Science Foundation of China (81100158), National Basic Research Program of China (973 Program, 2007CB512000, 


\section{Cellular Physiology and Biochemistry}

Cell Physiol Biochem 2013;32:1437-1450

Yu et al.: Cardiac Fibroblasts Could Recruit Th17 Cells

2007CB512005), and National Science and Technology Support Program (2011BAI11B00, 2011BAI11B23).

\section{References}

1 Dennert R, Crijns HJ, Heymans S: Acute viral myocarditis: Eur Hear J 2008;29:2073-2082.

-2 Deonarain R, Cerullo D, Fuse K, Liu PP, Fish EN: Protective role for interferon-beta in coxsackievirus B3 infection. Circulation 2004;110:3540-3543.

3 Liu PP, Mason JW: Advances in the understanding of myocarditis. Circulation 2001;104:1076-1082.

4 Cooper LT Jr: Myocarditis. N Engl J Med 2009;360:1526-1538.

5 Yuan J, Cao AL, Yu M, Lin QW, Yu X, Zhang JH, Wang M, Guo HP, Liao YH: Th17 cells facilitate the humoral immune response in patients with acute viral myocarditis. J Clin Immunol 2010;30:226-234.

6 Yuan J, Yu M, Lin QW, Cao AL, Yu X, Dong JH, Wang JP, Zhang JH, Wang M, Guo HP, Liao YH: Neutralization of IL-17 inhibits the production of anti-ANT autoantibodies in CVB3-induced acute viral myocarditis. Int Immunopharmacol 2010;10:272-276.

7 Yuan J, Yu M, Lin QW, Cao AL, Yu X, Dong JH, Wang JP, Zhang JH, Wang M, Guo HP, Cheng X, Liao YH: Th17 cells contribute to viral replication in coxsackievirus B3-induced acute viral myocarditis. J Immunol 2010;185:4004-4010.

-8 Liao YH, Xia N, Zhou SF, Tang TT, Yan XX, Lv BJ, Nie SF, Wang J, Iwakura Y, Xiao H, Yuan J, Jevallee H, Wei F, Shi GP, Cheng X: Interleukin-17A contributes to myocardial ischemia/reperfusion injury by regulating cardiomyocyte apoptosis and neutrophil infiltration. J Am Coll Cardiol 2012;59:420-429.

-9 Baldeviano GC, Barin JG, Talor MV, Srinivasan S, Bedja D, Zheng D, Gabrielson K, Iwakura Y, Rose NR, Cihakova D: Interleukin-17A is dispensable for myocarditis but essential for the progression to dilated cardiomyopathy. Circ Res 2010;106:1646-1655.

10 Bromley SK, Mempel TR, Luster AD: Orchestrating the orchestrators: chemokines in control of T cell traffic. Nat Immunol 2008;9:970-980.

11 Acosta-Rodriguez EV, Rivino L, Geginat J, Jarrossay D, Gattorno M, Lanzavecchia A, Sallusto F, Napolitani G: Surface phenotype and antigenic specificity of human interleukin 17-producing T helper memory cells. Nat Immunol 2007;8:639-646.

12 Metzler B, Mair J, Lercher A, Schaber C, Hintringer F, Pachinger O, Xu Q: Mouse model of myocardial remodelling after role of intercellular adhesion molecule-1. Cardiovasc Res 2001;49:399-407.

13 Nishio R, Matsumori A, Shioi T, Ishida H, Sasayama S: Treatment of experimental viral myocarditis with interleukin-10. Circulation 1999;100:1102-1108.

-14 Rui T, Cepinskas G, Feng Q, Ho YS, Kvietys PR: Cardiac myocytes exposed to anoxiareoxygenation promote neutrophil transendothelial migration. Am J Physiol Heart Circ Physiol 2001;281:H440-447.

-15 Yu Q Watson RR, Marchalonis JJ, Larson DF: A role for T lymphocytes in mediating cardiac diastolic function. Am J Physiol Heart Circ Physiol 2005;289:H643-651.

16 Bowden RA, Ding ZM, Donnachie EM, Petersen TK, Michael LH, Ballantyne CM, Burns AR: Role of alpha4 integrin and VCAM-1 in CD18-independent neutrophil migration across mouse cardiac endothelium. Circ Res 2002;90:562-569.

-17 Lim YC, Luscinskas FW: Isolation and culture of murine heart and lung endothelial cells for in vitro model systems. Methods Mol Biol 2006;341:141-154.

-18 Kokura S, Wolf RE, Yoshikawa T, Granger DN, Aw TY: T-lymphocyte-derived tumor necrosis factor exacerbates anoxia-reoxygenation-induced neutrophil-endothelial cell adhesion. Circ Res 2000;86:205213.

-19 Antoniak S, Owens AP 3rd, Baunacke M, Williams JC, Lee RD, Weithäuser A, Sheridan PA, Malz R, Luyendyk JP, Esserman DA, Trejo J, Kirchhofer D, Blaxall BC, Pawlinski R, Beck MA, Rauch U, Mackman N: PAR-1 contributes to the innate immune response during viral infection. J Clin Invest. 2013;123:1310-1322.

-20 Turner JE, Paust HJ, Steinmetz OM, Peters A, Riedel JH, Erhardt A, Wegscheid C, Velden J, Fehr S, Mittrücker HW, Tiegs G, Stahl RA, Panzer U: CCR6 recruits regulatory T cells and Th17 cells to the kidney in glomerulonephritis. J Am Soc Nephrol 2010;21:974-985. 


\section{Cellular Physiology and Biochemistry}

Cell Physiol Biochem 2013;32:1437-1450

\begin{tabular}{l|l}
\hline DOI: $10.1159 / 000356581$ & (c) 2013 S. Karger AG, Basel
\end{tabular}

Yu et al.: Cardiac Fibroblasts Could Recruit Th17 Cells

21 Reboldi A, Coisne C, Baumjohann D, Benvenuto F, Bottinelli D, Lira S, Uccelli A, Lanzavecchia A, Engelhardt B, Sallusto F: C-C chemokine receptor 6-regulated entry of TH-17 cells into the CNS through the choroid plexus is required for the initiation of EAE. Nat Immunol 2009;10:514-523.

-22 Hirota K, Yoshitomi H, Hashimoto M, Maeda S, Teradaira S, Sugimoto N, Yamaguchi T, Nomura T, Ito H, Nakamura T, Sakaguchi N, Sakaguchi S: Preferential recruitment of CCR6-expressing Th17 cells to inflamed joints via CCL20 in rheumatoid arthritis and its animal model. J Exp Med 2007;204:2803-2812.

-23 Liu J, Zhang N, Li Q, Zhang W, Ke F, Leng Q, Wang H, Chen J, Wang H: Tumor-associated macrophages recruit CCR6+ regulatory $\mathrm{T}$ cells and promote the development of colorectal cancer via enhancing CCL20 production in mice. PLoS One 2011;6:e19495.

24 Kao CY, Huang F, Chen Y, Thai P, Wachi S, Kim C, Tam L, Wu R: Up-regulation of CC chemokine ligand 20 expression in human airway epithelium by IL-17 through a JAK-independent but MEK/NF-KB-dependent signaling pathway. J Immunol 2005;175:6676-6685.

-25 Hirata T, Osuga Y, Takamura M, Kodama A, Hirota Y, Koga K, Yoshino O, Harada M, Takemura Y, Yano T, Taketani Y: Recruitment of CCR6-expressing Th17 cells by CCL20 secreted from IL-1 beta-, TNF-alpha-, and IL-17A-stimulated endometriotic stromal cells. Endocrinology 2010;151:5468-5476.

-26 Kanda N, Shibata S, Tada Y, Nashiro K, Tamaki K, Watanabe S: Prolactin enhances basal and IL-17-induced CCL20 production by human keratinocytes. Eur J Immunol 2009; 39:996-1006.

-27 Springer TA: Traffic signals for lymphocyte recirculation and leukocyte emigration: the multistep paradigm. Cell 1994;76:301-314.

-28 Luster AD, Alon R, von Andrian UH: Immune cell migration in inflammation: present and future therapeutic targets. Nat Immunol 2005;6:1182-1190.

29 Ley K, Laudanna C, Cybulsky MI, Nourshargh S: Getting to the site of inflammation: the leukocyte adhesion cascade updated. Nat Rev Immunol 2007;7:678-689.

-30 Ley K, Kansas GS: Selectins in T-cell recruitment to non-lymphoid tissues and sites of inflammation. Nat Rev Immunol 2004;4:325-335.

31 Xie Y, Liao J, Li M, Wang X, Yang Y, Ge J, Chen R, Chen H: Impaired cardiac microvascular endothelial cells function induced by Coxsackievirus B3 infection and its potential role in cardiac fibrosis. Virus Res 2012;169:188-194.

- 32 Sutton CE, Mielke LA, Mills KH: IL-17-producing $\gamma \delta$ T cells and innate lymphoid cells. Eur J Immunol 2012;42:2221-2231.

-33 Brodlie M, Lordan J, Ward C: Can cells other than Th17 lymphocytes be important sources of IL-17 in the lungs? Thorax 2011;66:1096-1097. 